\title{
The Value of the Liberal Arts and What it Means for Orientation Professionals
}

\author{
Penny Fripp Jones
}

The university was founded on a tradition of liberal arts education, but in recent years, attention to these fields has diminished. The current study examined the hiring of liberal arts graduates by businesses, in the hopes that orientation professionals can use the findings to help new students overcome fears and misconceptions about the value of a liberal arts degree.

Orientation professionals often find themselves in a position of brokering information, particularly among colleagues in admissions and career centers, related to student choices. A frequent conversation has to do with student major selection, a conversation often repeated in parent orientation programs. The current study was developed to identify a value of liberal arts majors as determined by business hiring, the hope of awakening a conversation among orientation professionals about the freedom of student choice, independence, and the academic experience.

An educational evolution cannot be disregarded, and the impact has been noticeable in the liberal arts (Bloom, 1987). A decline in the enrollment of liberal arts students has been indicated over the last decade, and the assertion is that the degree is not relevant in current business settings (Hersh, 1997).

Research is turning to the student of the liberal arts to gain a more comprehensive understanding of the discipline. The expectations and attitudes of these learners offer an added dimension to the liberal arts value, and studies conducted on student cultures lend themselves to close scrutiny for determining related characteristics among groups. Job relevance is a meaningful consideration, and student perceptions are as significant as reality. Educators must define liberal arts before they can support a mission. Institutional direction is lost through the avoidance of dogmatism, and the practical value of an education is all that remains to offer students (Wilshire, 1990).

While a strong program of practicality is called for, the liberal arts are essential for fulfilling educational breadth. An argument by Rosovsky (1991) has presented a dual view of the university. While strongly supporting the classical application of learning, including lifetime learning and ethical responsibility, he called for a presentation of best-practice balance. Liberal education must direct a purpose, and educators are called on to give meaning to learning that will transfer as practical experience in dealing with complex situations (Kuh, Douglas, Lund, \& Ramin-Gyurnek, 1994).

Partnering with business allows the opportunity to adjust for relevance. Miller and Evans (1997) surveyed continuing education directors in 2- and 4-year higher education institutions and human resources/relations directors from business and industry to

Penny Fripp Jones, M.A., is currently doing foundational work at Georgia State University towards a doctoral degree in higher education. Her background includes transitional counseling and consulting in financial aid. 
determine if institutions are meeting the perceived training needs of business. The results indicated that employers are not united in defining objectives for educators. While lifelong learning is a common goal, other requirements are less direct. An exchange of ideas is called for if the training and retraining needs of industry are to be met.

Widely acknowledged confusion and lack of direction result in a body of research that has attempted to respond to a need for student fulfillment. Consideration and observation of student cultures will give direction for educational success in placing a liberal arts learner (Pascarella \& Terenzini, 1991). Awareness of the liberal arts value can be imparted through research, career center initiatives, and orientation at both college and secondary levels. Knowledge of liberal arts outcomes will allow students to make informed decisions.

Educators agree that the hiring practices of business can create an index for educational value (Useem, 1989), and a survey of employment practices can supply vital information for creating relevancy. This, in turn, can supply important information to orientation leaders as they look to have serious conversations about the impact of major choice. As the front-line of college-life advising, these professionals can do a great deal to discard the myths surrounding the value of a liberal arts degree.

\section{Methods}

By examining the employment records of liberal arts graduates, a representation emerges of the applied attitudes of those who are hiring. The current study was conducted to determine if the liberal arts degree shows recognized value as indicated by business hiring practices. Measuring to what degree businesses are employing students of the liberal arts is a means for indicating the maintained performance value of a liberal arts degree. And subsequently, orientation professionals are thus better prepared to add to the conversation about major selection.

Quantitative data was collected from the career center files of four campuses. The University of Georgia, in Athens, Georgia, a state institution provided information to be viewed with that of the Georgia Institute of Technology, the College of Charleston in Charleston, South Carolina, and the University of the South in Sewanee, Tennessee. These institutions were selected because of their willingness to participate, their proximity to the researcher, and due to their assumed differences in how they offer a liberal arts education.

Business hiring practices were mapped for a five-year period using statistical records indicating the number of liberal arts students employed. Percentages indicated liberal arts hiring as well as a mean score given for employment results of the four schools observed.

Targeting regional and national schools for the study promoted the diversity needed to establish reliability, and records were also examined for accuracy. The research attempted to establish a comprehensive and accurate picture of the appreciation that business employment has for the liberal arts student. 


\section{Results}

The data for the business indices on hiring practices at the University of Georgia were given as percentages for the last 4 years. The statistics indicated representative students hired from the graduating class with no recorded data for those attending graduate school in some cases. For the purpose of the research, the difference was calculated for observation. The vocational/professional statistic was calculated as an average of the schools outside of the arts and sciences (see Table 1).

There was no notable difference in the hiring of liberal arts and professional/ vocational students for the 4 recorded years. The greatest distinction was indicated for the earliest recorded year, which was 1994-1995. The findings support a stable hiring trend for liberal arts majors at this institution.

Another consideration is that of graduate students. In most cases data was not available to examine the effect of this population on the statistics given. The liberal arts degree promoted the pursuit of a postgraduate degree, and a number of students are expected to continue their education immediately after undergraduate school, frequently precluding full-time employment.

Career Services at the Georgia Institute of Technology surveyed graduates to ascertain post-graduation plans. Findings were determined from the response cards returned by $92 \%$ of the students $(n=1,243)$. The Dupree College of Management and the Ivan Allen College are presented as a $13 \%$ liberal arts constituency because of the broad range of humanitarian courses offered. Thirteen percent of all bachelor candidates were accepted to graduate school, but statistically were not separated by departments. Employment data were recorded for 1998-1999 only (see Table 2).

The limited data recorded at the Georgia Institute of Technology shows a higher employment rate for the professional field student. While the school has a strong reputation in engineering, it has supplemented a liberal arts agenda as a retention effort in recent years. Career center efforts to place the concentration of engineering students may be responsible for this observation. Also, the overlap of figures for graduate students allows for miscalculations.

The employment data at the College of Charleston were available from alumni surveys extending from 1992-93 to 1997 that were sent to graduates in the spring following the student's commencement (see Table 3). Statistics represented a sample from the total graduating population, and response rates ranged from $25 \%$ in 1992-1993 to $20 \%$. Although these are low, they are considered representative. The College of Charleston Office of Institutional Research and Planning conducted the surveys presented from 1992-1997. The 1998 statistics were drawn from career center research. Totals were not computed due to an overlap in graduate students with full-time employment, which in some cases calculated over $100 \%$.

A difference of 8.3\% was important for employment indices between 1992-1993 and 1993-1994. A rise occurred in the hiring taking place on this liberal arts campus since 1992-1993, and the inclusion of graduate school statistics permits accurate findings from the respondents. The data indicates a high rate of employment for College of Charleston students. 
From survey statistics solicited in the summer and fall after graduation, graduate employment results were collected for the classes of 1994 through 1997 at the University of the South (see Table 4). These statistics demonstrate a rise in the number of students going directly to graduate school with a nearly $20 \%$ decrease in employment upon graduation.

\section{Discussion}

The perception has grown that the students of the liberal arts have been overlooked, and that these humanities have lost relevance in a career-based world (Willemon, \& Naylor, 1995). Strong marketing, backed with substantial funding, has created a public preoccupation with vocational goals, and at the same time liberal arts educators take exception at having to defend a practical component. The worth of a service or product can be diminished by a lack of recognized value, and literature presents a declining state of the liberal arts that is not documented in current data.

The hiring practices of business seem to vindicate those who have held on to the belief that value is inherent in the liberal arts. Statistics out of the subject career centers support the notion of a cyclical assumption. The turn in employment and rise in economy that have occurred in recent years brought a moderate increase in the hiring of liberal arts students, but more importantly, employment of these students has remained at a level with other disciplines.

A useful and direct approach might take advantage of the growing popularity of continuing education on campuses across the nation. Students and providers who have a role in college decision-making often turn to classes for information and understanding to guide these transitions. Through adult education, universities now have the opportunity to offer courses that address numerous topics informing the selection process. There are enough subjects of current and historical interest that entire departments can evolve from this issue. Student advisors at the secondary level will benefit from knowledge that can enlighten student expectations for a chosen degree and make matching goals to outcomes more reliable. Orientation professionals can implement valuable links to secondary education by delivering information on educational choices that can be passed on to students before the decision process begins. The vocational purpose that maintains continued interest among constituents should be balanced with an understanding of the liberal arts intention. These contributions can result in fewer transfers and an overall higher college retention rate.

Career centers can be valuable campus resources as well. Orientation professionals can use these facilities for disseminating information to balance curricular understanding.

Research tied to and perpetuating the usefulness and recognition of liberal arts characteristics for business applications demonstrates relevance for a neglected degree that shows enormous returns for student success. With such studies, university sources can readily assist college applicants in making appropriate curriculum choices, and direct attention to the value of liberal arts learning. While "short-order" slots may be readily filled by employers looking for applicants who are job ready, traditional coursework prepares students for a lifetime of business growth. 
The privileged charge of education is to guide citizenry. So educators have the responsibility to find answers and make the corrections that are necessary for devising effective student transitions. And orientation professionals have the doubly important role of helping new students see themselves as life-long learners who value from the critical thinking and communication skills gained in liberal studies, and to see that new students take the time necessary to make informed, reasoned, and purposeful academic major choices.

\section{References}

Bloom, A. (1987). The closing of the American mind: How higher education has failed democracy and impoverished the souls of today's students. New York: Simon and Schuster.

Hersh, R. H. (1997). The Liberal arts college: The most practical and professional education for the twenty-first century. Liberal-Education, 83(3) 26-33.

Kuh, G. D., Douglas, K. B., Lund, J. P., \& Ramin-Gyurnek, J. (1994). Student learning outside the classroom: Transcending artificial boundaries. (ERIC Document Reproduction Service No. ED 394 443).

Miller, M. T., \& Evans, J. P. (1997). Higher education's preparedness to fulfill business and industry training needs. Catalyst, 26 (3), 7-10.

Pascarella, E. T., \& Terenzini, P. T. (1991). How college affects students: Findings and insights from twenty years of research. San Francisco: Jossey-Bass.

Rosovsky, H. (1991). The university-An owner's manual. NY: Norton \& Co.

Useem, M. (1989). Liberal education and the corporation. The hiring and advancement of college graduates. Hawthorne, NY: Aldine de Gruyter.

Willemon, W. H., \& Naylor, T. H. (1995). The abandoned generation: Rethinking higher education. Grand Rapids, MI: William B. Eerdmans.

Wilshire, B. (1990). The moral collapse of the university. Albany, NY: State University of New York 
The University of Georgia Graduating Student Business Hiring by Major Area

Business hiring

1994-1995

1995-1996

1996-1997

1997-1998

from these disciplines

\begin{tabular}{lllll}
\hline Arts and Sciences & $93 \%$ & $87 \%$ & $93 \%$ & $94 \%$ \\
Vocational/professional & $95 \%$ & $88 \%$ & $94 \%$ & $95 \%$
\end{tabular}

\section{TABLE 2}

The Georgia Institute of Technology Graduate Hiring

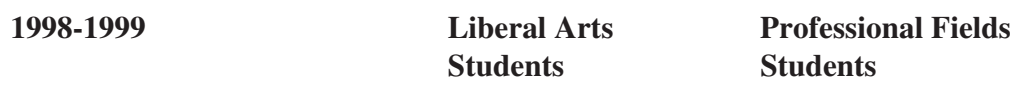

Full-time employment

or graduate school

$60 \%$

$70 \%$

TABLE 3

College of Charleston Graduating Student Hiring

\begin{tabular}{lccccc} 
& $\mathbf{1 9 9 2 - 1 9 9 3}$ & $\mathbf{1 9 9 3 - 1 9 9 4}$ & $\mathbf{1 9 9 4 - 1 9 9 5}$ & $\mathbf{1 9 9 5 - 1 9 9 6}$ & $\mathbf{1 9 9 6 - 1 9 9 7}$ \\
\hline $\begin{array}{l}\text { Response rate } \\
\begin{array}{l}\text { Graduate school } \\
\text { (full-time only) }\end{array}\end{array}$ & $25 \%$ & $24 \%$ & $20 \%$ & $22 \%$ & $22 \%$ \\
$\begin{array}{l}\text { Full-time } \\
\text { employment }\end{array}$ & $14 \%$ & $33 \%$ & $29 \%$ & $23 \%$ & $25 \%$ \\
\hline
\end{tabular}

TABLE 4

The University of the South Graduate Employment

\begin{tabular}{lcccc} 
& $\mathbf{1 9 9 4}$ & $\mathbf{1 9 9 5}$ & $\mathbf{1 9 9 6}$ & $\mathbf{1 9 9 7}$ \\
\hline Responses & $50 \%$ & $52 \%$ & $57 \%$ & $57 \%$ \\
Employed & $87 \%$ & $80 \%$ & $75 \%$ & $65 \%$ \\
Graduate school & $13 \%$ & $18 \%$ & $24 \%$ & $30 \%$ \\
\hline
\end{tabular}

